\title{
INTERNALISASI PAHAM KESALEHAN DIGITAL DALAM PEMBELAJARAN PENDIDIKAN AGAMA ISLAM DI ERA CYBERCULTURE
}

\author{
Muhammad Candra Syahputra \\ Universitas Islam Negeri Raden Intan Lampung, Indonesia \\ Email: candrasyach@gmail.com \\ Dewi Puspo Rini \\ Pascasarjana Universitas Negeri Yogyakarta, Indonesia \\ Email: dewipuspo.2019@student.uny.ac.id
}

DOI : 10.24235/oasis.v5i2.7859
Received
Revised
Approved
2021-01-24
2021-01-30
2021-01-31

\begin{abstract}
The use of the internet is often misused, as seen from the widespread of fake news and issues that threaten national unity. The implementation of Islamic religious education is needed for internalizing the understanding of digital piety to students in the era of cyberculture. This research uses a qualitative approach, while the type of this research is library research sourced from library materials without conducting field research. Internalization understanding digital piety in learning Islamic religious education conducted by instilling an understanding of digital literacy, monitoring students' social media accounts, and effective communication between teacher and parents.
\end{abstract}

Keywords:Islamic Education, Digital Piety, Cyberculture Era

\begin{abstract}
Abstrak
Penggunaan internet sering disalahgunakan untuk menyebarkan berita bohong dan isu lainnya yang mengancam kesatuan bangsa. Penerapan pendidikan agama Islam yang menenkankan internalisasi paham kesalehan digital kepada peserta didik di era cyberculture sangat perlu dilakukan.. Penelitian ini menggunakan pendekatan kualitatif, adapun jenis penelitian ini adalah penelitian kepustakaan yang bersumber dari bahan-bahan pustaka tanpa melakukan penelitian di lapangan. Hasil penelitian ini membuktikan internalisasi paham kesalehan digital dalam pembelajaran pendidikan agama Islam dapat dilakukan dengan cara menanamkan pemahaman literasi digital, pengawasan akun media sosial peserta didik, dan komunikasi efektif antara guru dan orang tua.
\end{abstract}

Kata Kunci:Pendidikan Islam, Kesalehan Digital, Era Cyberculture

\section{Pendahuluan}

Indonesia merupakan Negara yang memiliki keragaman suku, budaya, dan agama. Keberagaman tersebut tentu menjadi suatu kekayaan yang dimiliki Bangsa Indonesia yang tidak dimiliki bangsa di belahan Dunia manapun, dan merupakan ciri khas Bangsa Indonesia. Masyarakat Indonesia sebagai masyarakat beragama masih sangat patuh dengan nilainilai religious agamanya. Masing-masing agama memiliki aturan dalam 
mengarahkan umatnya menjalani kehidupan ini agar dapat hidup dengan harmonis. Islam misalnya, menekankan pentingnya menjaga akhlak. Setidaknya, ada tiga hubungan yang perlu dijaga untuk menciptakan keharmonisan dan keseimbangan hidup.

Pertama yaitu hablu minallah atau hubungan manusia bagaimana umat dengan sang pencipta. Seorang muslim harus memiliki hubungan yang baik dengan Tuhannya. Hubungan manusia dan sang penciptanya tersebut tercermin dalam kepatuhan ibadah kepada-Nya dengan menjalankan perintah-Nya dan menjauhi segala larangan-Nya. Hal demikian disebut sebagai kesalehan spiritual. Kedua, Islam juga mengatur bagaimana hubungan manusia dengan manusia atau hablu minannas. Selain menjaga hubungan yang baik dengan sang pencipta, kita juga harus bersikap baik sesama manusia. Ketiga, hablu minal alam yaitu hubungan antara manusia dengan alam alam. Hubungan baik manusia dengan alam dapat terlihat dari bagaimana kita merawat dan melestarikan alam sekitarnya dan tidak merusak lingkungan.

Selanjutnya, di era cyberculture, penerapan hablu minnas dapat dalam bentuk bagaimana kita bersikap bijak dalam memanfaatkan sosial media untuk menebarkan kebaikan-kebaikan bagi sesama. Beberapa nilai-nilai kebaikan perlu diinternalisasikan melalui pembelajaran pendidikan agama Islam sebagai bentuk upaya mewujudkan generasi bangsa yang mampu dengan bijak memanfaatkan media digital dan bangsa yang berdaulat sehingga tidak mudah dipecah-belah melalui isu-isu yang disebarkan melalui media digital. Oleh karenanya, menciptakan sumber daya manusia yang menguasai teknologi, informasi, dan komunikasi melalui pendidikan menjadi penting (Wayong, 2017, hlm. 232),

Hal tersebut sangat dibutuhkan di tengah maraknya gerakan yang berpotensi merusak ideologi kebangsaan dan gerakan ideologi radikal yang disebarkan menggunakan internet melalui media sosial. Maka, perlu ditanamkan sikap yang menghargai keberagamaan kepada warga negara atau disebut civil religion (Irham, 2017, hlm. 145). Seiring berkembangnya teknologi, literasi digital merupakan hal yang penting (Syahputra, 2020c, hlm. 121). Di era digitial ini, sering kita jumpai ujaran-ujaran kebencian di sebarkan di media sosial.

Nasrulah dan Rustandi (2016) dalam penelitiannya menyatakan bahwa dengan bahasa agama, meme tidak sekadar menjadi bahasa yang literer saja, melainkan juga bisa tersirat. Pengguna media sosial menjadikan meme sebagai sarana dan bahasa untuk kritik yang dapat diarahkan dalam ruang agama. Dalam tulisannya tersebut juga dikatakan bahwa meme Islam banyak berbentuk simulakra kritik yang sangat halus namun tajam dalam menyampaikan pesannya. Berdasarkan penjelesan di atas, tulisannya bermaksud menyampaikan tentang internalisasi paham kesalehan digital dalam pembelajaran pendidikan agama islam di era cyberculture.

\section{Metode Penelitian}

Berdasarkan latar belakang di atas penulis merasa sangat perlu memberikan konsep tentang bagaimana Internalisasi Paham Kesalehan Digital Melalui Pembelajaran Pendidikan Agama Islam Di Era Cyberculture. Pendekatan yang digunakan dalam penelitian ini adalah 
pendekatan kualitatif (Dyah, 2005, hlm. 25). Metode dalam penelitian ini dilakukan dengan cara deskriptif-kualitatif dengan menggunakan kajian pustaka (library research). Penelitian ini merupakan penelitian kepustakaan, mencari dan menggali dari bermacam-macam sumber data yang berkaitan dengan permasalahan yang diteliti berupa dokumen kepustakaan (Sukardi, 2015, hlm. 34). Kajian pustaka adalah proses kegiataan menelaah bahanbahan pustaka tersebut (Sanjaya, 2015, hlm. 205), maka penulis tanpa melalui penelitian yang dilakukan di lapangan,

Penulis dalam penelitian ini menekankan pada kekuatan analisis sumber-sumber dan data-data yang ada dengan mengandalkan teori-teori dan konsep-konsep untuk kemudian di interpretasikan berdasarkan tulisan-tulisan yang relevan pada pembahasan.

\section{Hasil Dan Pembahasan}

1. Cyberculture

Saat ini, kita dihadapkan pada ketersediaan informasi yang melimpah. Sistem pertukaran informasi seperti memberi dan menerima informasi dapat dilakukan dengan cepat dan mudah sebagai bagian dari sirkuit informasi dalam cyberculture ('Uyun, 2020, hlm. 69).

Cyberculture terdiri atas dua kata yaitu cyber dan culture. Definisi dari cyber adalah segala sesuatu yang terdapat pada internet (Nasrullah \& Rustandi, 2016, hlm. 114). Secara harfiah arti cyberculture segala budaya atau kebiasaan yang telah atau sedang muncul dari penggunaan suatu jaringan komputer untuk saling berkomunikasi, bisnis, hiburan, pendidikan dan lain sebagainya yang berkaitan dengan dunia maya (Ismanto, 2018, hlm. 70).

Interaksi sosial melalui media online merupakan salah satu kebutuhan utama masyarakat saat ini. Cyberculture merupakan bentuk budaya kehidupan masyarakat modern dalam hubungan interaksi maupun ruang sosial secara online (Lestari, 2017, hlm. 4-5).

Di sisi lain, perkembangan penggunaan teknologi informasi dan media sosial yang semakin masif menyisakan kekhawatiran tentang adanya kemungkinan konflik kepentingan politis yang berpotensi memecahbelah persatuan bangsa dan merusak persatuan yang telah dirintis dan diinisasi oleh pendiri bangsa. Hasil penelitian terdahulu menyatakan, ujaran kebencian yang dilakukan di facebook $25 \%$ penistaan agama $25 \%$, berita bohong $20 \%$, pencemaran nama baik $15 \%$, provokasi $15 \%$ (Ningrum dkk., 2018, hlm. 251). Hal ini merupakan salah satu dampak negatif dari penggunaan media sosial dan tekonologi informasi yang ada. Fakta yang terjadi sebagaimana disebutkan di atas adalah bagian dari globalisasi yang mewariskan rentetan perubahan-perubahan yang sangat besar secara menyeluruh pada tatanan dunia (Oviyanti, 2013, hlm. 267).

\section{Kesalehan Sosial}

Kemajuan teknologi, informasi, dan komunikasi, tentu memberikan dampak yang positif juga dampak negatif terhadap Bangsa Indonesia. Dampak positif dari perkembangan teknologi menjadikan pekerjaan manusia lebih mudah. Perkembangan teknologi informasi semakin memudahkan kita untuk berinteraksi dengan orang lain tanpa 
adanya kendala jarak dan waktu. Internet awalnya sebagai sebuah model media komunikasi kini menjadi fenomena budaya baru atau new culture (Rohayati, 2017, hlm. 184). Tidak hanya itu, kini, teknologi informasi, media sosial juga digunakan untuk menyampaikan berita termasuk diantaranya adalah berita yang belum terkonfirmasi kebenarannya. Hal ini yang menjadi tantangan kita bersama bagaimana kita mampu membentengi diri, keluarga, dan lingkungan sekitar dari pengaruh buruk perkembangan informasi dan komunikasi tersebut. Banyaknya informasi palsu serta berita bohong yang beredar disekitar kita serta adanya informasi bermuatan negatif yang berupa ujaran kebencian, menunjukkan bahwa pengguna internet dan media sosial belum mengamalkan kesalehan digital (Kholidi, 2016).

Kata saleh berasal dari bahasa Arab dari kata shalih memiliki beberapa makna seperti baik, dan menolak kerusakan.Orang saleh berarti orang yang melakukan kebaikan. Penyebutan saleh merujuk kepada orang-orang yang beriman (Saepududin dkk., 2020, hlm. 242-244). Amal saleh bermakna aktivitas atau perbuatan yang baik. M. Quraish Shihab mengatakan bahwa arti amal saleh sebagai amal yang diterima, dan dipuji oleh Allah (Shihab, 1997, hlm. 753). Dalam al-Qur'an dan Hadits sangat banyak menerangkan agar kita sebagai umat muslim untuk senantiasa beramal saleh (Falah, 2016, hlm. 169). Paham kesalehan digital adalah suatu paham tentang bijak menggunakan media digital atau bagaimana kita berbuat baik sesama pengguna media sosial.

\section{Paham Kesalehan Digital Dalam Pembelajaran Pendidikan Agama Islam Di Era Cyberculture}

Penanaman tentang paham kesalehan digital kepada para peserta didik menekankan tentang pentingnya memiliki bijak dalam memanfaatkan media digital. Dalam praktiknya, internalisasi paham kesalehan digital dilakukan dengan cara memberikan materi pengajaran tentang pentingnya memiliki sikap baik (akhlakul karimah). Pembelajaran pendidikan agama Islam tidak hanya menekankan pada penguasaan teori tapi juga pengamalanya dalam kehidupan sehari-hari di dunia nyata.

Pendidikan menjadi tempat yang sistematis untuk menanamkan nilai-nilai tersebut demi mewujudkan generasi emas sesuai yang dicita-citakan oleh Kementrian Pendidikan dan Kebudayaan. Perkembangan teknologi, informasi, dan komunikasi membuka selebar-lebarnya akses informasi dari seluruh penjuru dunia (Nurjanah dkk., 2017, hlm. 118). Pendidikan merupakan sistem dan cara yang paling tepat untuk meningkatkan kualitas dalam segala aspek kehidupan manusia (Sanaky, 2003, hlm. 4).

Pendidikan agama Islam yang membawa misi religiusitas juga ikut mengambil bagian untuk berperan di era digital dengan membekali keimanan, ketakwaan, ilmu pengetahuan, dan keterampilan yang seimbang agar mampu menciptakan peserta didik yang siap menghadapi segala tantangan di era cyberculture (Syamsirin, 2012, hlm. 277278).

Indonesia memiliki keragaman suku, budaya, dan tradisi. Hal tersebut menjadi modal besar yang dimiliki bangsa Indonesia untuk membangun khazanah kehidupan bernegera. Satu dengan lainnya 
dapat saling memperkaya untuk terwujudnya kehidupan yang harmoni (Naim, 2016, hlm. 424). Di sisi lain, perbedaan tersebut juga berpotensi menimbulkan suatu perpecahan. Salah satunnya disebabkan oleh penyebaran informasi, berita, konten, dan hal-hal lainnya melalui media sosial yang bermuatan negatif, cenderung memecah belah bangsa. Contohnya, jika kita menulis di mesin pencari google kemudian kita masukan kata kunci 'konflik' maka yang paling banyak muncul adalah konflik antar suku, antar agama, antar budaya, dan perbedaan yang semestinya tidak perlu dibesar-besarkan (Syahputra, 2020b, hlm. 82). Maka, setidaknya ada tiga hal yang perlu dilakukan oleh seorang guru dalam menanamkan paham Kesalehan Digital Dalam Pembelajaran Pendidikan Agama Islam Di Era Cyberculture.

\section{a. Character Building}

Secara umum, tujuan pendidikan adalah melahirkan manusia yang memiliki akhlak yang baik. Sikap baik perlu ditunjukkan dalam kehidupan nyata maupun di kehidupan maya. Sehingga, turut menyebarkan berita bohong, provokatif, serta mengandung ujuran kebencian dan berpotensi memecah persatuan tentu harus dihindari. Tujuan pendidikan adalah menjadikan manusia yang berbudi pekerti luhur, tentu ujaran kebencian tersebut tidak selaras dengan tujuan pendidikan (Sujana, 2019, hlm. 31-32).

Maju dan mundurnya suatu bangsa ditentukan oleh kualitas sistem pendidikannya. Berkaca atas kemerosotan karakter, pemerintah melalui Kementrian Pendidikan dan Kebudayaan yang juga menjadi Peraturan Presiden tentang Penguatan Pendidikan Karakter (PPK). PPK sebagai bentuk nyata pemerintah dalam mengatasi dekadensi karakter. Namun demikian, menurut Reza Ahmad Zahid sebelum masuk kepada pembahasan character building, harus memprioritaskan transformasi nilai-nilai agama, dan moral (Zahid, 2013, hlm. 9).

Dari pendapat di atas menujukkan pentingnya pendidikan agama Islam sebagai mata pelajaran yang harus lebih diprioritaskan dalam menanamkan nilainilai religius yang dapat membentuk suatu kesadaran hubungan satu sama lain dengan baik. Tidak mampunya pendidikan agama dalam menanamkan sikap inklusif kepada para peserta didiknya itu dikarenakan isi dalam pendidikan agama lebih padat materi yang orientasinya pada pemikiran, daripada membangun kesadaran beragama yang utuh (Abdul, 2012, hlm. 5). Lebih mengkhawatirkan lagi apabila sikap tidak inklusif peserta didik tersebut diekspresikan di dunia maya yang dapat diakses dari segala penjuru negeri bahkan dunia, sehingga menimbulkan ketidak harmonisan hubungan satu sama lain di dunia maya yang berimbas pada hubungan secara langsung di dunia nyata.

\section{b. Moderat}

Selain pembentukan karakter siswa didik, pola pendidikan juga perlu menciptakan, mengkolaborasi, atau megelaborasi pembelajaran pendidikan agama Islam yang mampu mentransformasikan nilai-nilai moderat. Menurut Toto Suharto, lembaga pendidikan Islam dapat memasang konsep baik, dan konsep nilai yang terkandung dalam moderatisme tersebut ke dalam tujuan pendidikannya (Suharto, 2017, hlm. 167-168). Dalam pendapat lain yang dikemukakan Syamsul Arifin:

\begin{tabular}{l}
\multicolumn{2}{c}{ "Perlunya } \\
pengembangan suatu model pendidikan \\
yang dapat mencegah terjadinya \\
infiltrasi paham radikal. Model ini \\
perlu mengacu pada suatu desain utuh \\
yang memuat: kerangka pandang yang \\
mendasar terhadap islam; materi, \\
model pembelajaran, serta lingkungan \\
yang dapat menumbuhkan
\end{tabular}


pengetahuan, dan sikap pengakuan, toleran, dan kooperatif terhadap pihak yang berbeda baik karena alasan agama, paham keagamaan, budaya, dan lain sebagainya. Model tersebut dapat disebut model pendidikan multikultural, seperti halnya banyak contoh hasil eksplorasi dan elaborasi dibidang ini seperti buku Pendidikan Agama Islam dalam perspektif multikulturalisme yang diterbitkan Balai Penelitian dan Pengembangan Agama Jakarta tahun 2009" (Arifin, 2014, hlm. 411).

Kutipan di atas menekankan pentingnya menanamkan nilai toleransi, moderatisme, dengan mengembangkan model pendidikan agama Islam berwawasan multikultural. Sikap pengakuan atau multikulturalisme, perlu ditanamkan tidak hanya pada kehidupan sehari-hari secara langsung dalam dunia nyata, namun juga perlunya ditanamkan sikap multikultural di dunia maya. Pada era cyberculture atau budaya internet pendidikan agama Islam perlu juga menanamkan nilai moderat, multikultural, dan plural untuk mewujudkan kesalehan sosial dalam kehidupan di dunia nyata dan kesalehan digital dalam interaksi di dunia maya.

Saat ini kita dapat dengan mudah mendapatkan informasi yang menyodorkan menganai isu-isu yang menyinggung suku, agama, ras, dan antar golongan (SARA), bahkan paham radikal (Muthohirin, 2015, hlm. 240). Pemahaman multikultural dapat meminimalisir dampak negatif dari berita bohong atau hoax yang bisa menciptakan ketegangan dan memecah-belah bangsa.

\section{c. Multidisipliner}

Selain tujuan di atas, perlu melakukan kajian mengenai Internalisasi Paham Kesalehan Digital Melalui Pembelajaran Pendidikan Agama Islam Di Era Cyberculture perlu untuk menambah kajian keislaman (Islamic studies) dalam pendidikan, utamanya dalam pengembangan pendidikan agama Islam berbasis multidisipliner. Hal ini sesuai dengan ajaran agama Islam yang memiliki kandungan ajaran yang multidimensional (Qomar, 2019, hlm. 1-3). Pendidikan agama Islam tidak hanya bermuatan materi bagaimana hubungan manusia dengan Tuhan, tetapi juga berisi bagaimana hubungan manusia dengan manusia. Internalisasi paham kesalehan digital dalam pembelajaran pendidikan agama Islam yaitu dengan menanamkan pemahaman tentang literasi digital kepada peserta didik, melakukan pengawasan terhadap akun media sosial peserta didik, dan mengkomunikasikan dengan orang tua peserta didik.

Pengajaran pendidikan Agama Islam, secara khusus perlu melakukan langkahlangkah:

1. Menanamkan pemahaman literasi digital kepada peserta didik, dalam hal ini guru berperan dalam melakukan sosialisasi pada peserta didik tentang pentingnya literasi digital saat proses pembelajaran pendidikan agama Islam berlangsung. Seperti yang kita ketahui, media sosial seringkali digunakan sebagai alat untuk menyebaran isu bermuatan SARA yang cenderung memecah belah bangsa. Kemudian, agama merupakan salah satu isu yang seringkali digunakan oleh beberapa oknum untuk memperoleh keuntungan pribadi, misalnya saja pada Pilkada DKI 2017. Isu agama digunakan oleh pihakpihak tertentu (Kurniawan, 2018, hlm. 134). Hal ini tentu berpotensi mencederai demokrasi Republik ini.

Beberapa komunitas keagamaan juga merespon maraknya penyebaran berita bohong, ujaran kebencian yang memainkan sentiment SARA seperti gerakan yang dilakukan Arus Informasi Santri Nusantara yaitu komunitas santri yang bergerak di dunia maya melakukan berbagai gerakan literasi digital di pesantren-pesantren dengan 
memberikan pelatihan kepada para santri sebagai bekal keterampilan santri dalam menyebarkan dakwah yang ramah (Syahputra, 2020a, hlm. 69-78).

Internalisasi dalam pembelajaran pendidikan agama Islam materi tentang digital literasi dan juga pemahaman kesalehan digital di sekolah-sekolah secara sistematis untuk menciptakan generasi masa depan yang terampil dalam memanfaatkan media internet serta bijak dalam bermedia sosial berlandaskan nilai-nilai nasionalisreligius sesuai dengan cita-cita Demokrasi Indonesia.

2. Melakukan pengawasan terhadap akun media sosial peserta didik. Media sosial adalah platform yang paling banyak digunakan dari semua kalangan untuk berinteraksi satu sama lain, dan paling banyak digunakan oleh kalangan milenial. Pendidikan di era ini harus dapat mengarahkan seseorang menjadi manusia yang baik dan bijak dalam memanfaatkan perkembangan teknologi, informasi, dan komunikasi. Oleh karena itu, pemberian pendidikan literasi digital di sekolah-sekolah maupun madrasah, perlu dilakukan karena pengguna terbanyak media digital salah satunya adalah media sosial adalah kaum millennial (Afwiyana dkk., 2019, hlm. 40). Namun, pengawasan perlu terus dilakukan oleh guru agar mereka tidak dengan mudah mempercayai konten yang ada di media sosial. Kaum millennial itu merupakan kelompok yang diindikasi masih duduk dibangku sekolah hingga perguruan tinggi dan memiliki cenderung dengan mudah menyebarkan informasi yang dirasa penting, padahal informasi tersebut adalah berita bohong (Afifah dkk., 2019, hlm. 74).

3. Guru mengkomunikasikan dengan orang tua. Masa remaja adalah masa dimana seorang individu memiliki kecenderungan mencoba hal-hal baru.
Namun, yang patut kita waspadai adalah saat individu tersebut tidak hanya mencoba hal baru yang bernilai positif, tetapi juga mencoba hal-hal baru yang cenderung kearah negatif. Peserta didik dapat dengan mudah mengakses konten negatif berupa pornografi dan lain sebagainya melalui smartphone. Dalam melakukan pengawasan terhadap peserta didik tentu memiliki keterbatasan. Oleh karena itu, seorang guru tentu tidak dapat secara penuh dalam melakukan pengawasan, sehingga mereka membutuhkan orang tua peserta untuk juga mengawasi anakanaknya Maka, guru pendidikan agama Islam perlu mengkomunikasikan kepada orang tua untuk membimbing dan melakukan pengawasan penggunaan smartphone agar peserta didik terhindar dari konten negatif.

Internalisasi paham kesalehan digital melalui pembelajaran pendidikan agama Islam akan maksimal apabila ketiga hal di atas dapat berjalan dengan baik guna membentuk generasi milenial sebagai penerus bangsa yang memiliki sikap, nasionalis, dan religius demi terciptanya kemajuan Negara Kesatuan Republik Indonesia.

\section{Kesimpulan}

Era cyberculture sebagai era keterbukaan, tentu hal ini menjadi keuntungan untuk mempermudah pekerjaan manusia. Namun disisi lain bagaikan pisau bermata ganda, selain memberikan manfaat positif juga dapat berdampak negatif bagi kita, bahkan tidak hanya orang tua, anak-anak juga menjadi korban dampak negatif perkembangan teknologi informasi dan komunikasi, seperti persebaran berita bohong, isu-isu yang bermuatan radikal, sampai pada isu yang memecah-belah bangsa. Oleh karenanya, pendidikan menjadi salah satu kunci untuk mencegah dekadensi karakter bangsa, hal ini tentu perlu terlebih dahulu penanaman nilai-nilai religius melalui 
pembelajaran pendidikan agama Islam dengan menanamkan paham kesalehan digital di era cyberculture melalui penanaman paham literasi digital, pengawasan akun media sosial peserta didik oleh guru, dan guru menjalin komunikasi kepada orang tua peserta didik untuk melakukan pengawasan penggunaan perangkat internet.

\section{Daftar Pustaka}

Abdul, F. (2012).Budaya Toleransi Dalam Pembelajaran Pendidikan Agama Islam.SPS UIN Syarif Hidayatullah Jakarta.

Afifah, L., Muhlis, A., \& Fatoni, U. (2019).Strategi Dakwah Santri dalam Menghadapi Berita Hoax di Media Sosial.Prophetica: Scientific and Research Journal of Islamic Communication and Broadcasting, 5(1).

Afwiyana, N. D., Amrozi, Y., \& Falihah, T. (2019).Langkah Cerdas Bermedia Sosial di Kalangan Santri Milenial.SAINTEKBU: Jurnal Sains dan Teknologi, 11(2).

Arifin, S. (2014). Membendung Arus Radikalisasi di Indonesia. ISLAMICA: Jurnal Studi Keislaman, 8(2).

Dyah, H. M. (2005). Penelitian Kualitatif Dalam Penerapan. Depdiknas Pusat Bahasa.

Falah, R. Z. (2016). Membentuk Kesalehan Individual dan Sosial Melalui Konseling

Multikultural.KONSELING RELIGI: Jurnal Bimbingan Konseling Islam, 7(1).

Irham, M. A. (2017). Civil Religion dan Masa Depan Umat Beragama di Indonesia: Mempertemukan Ideologi Keagamaan dan Ideologi Kebangsaan. Al-Adyan: Jurnal Studi Lintas Agama, 12(2).

Ismanto, I. (2018). Budaya Selfie Masyarakat Urban: Kajian Estetika Fotografi, Cyber Culture, dan
Semiotika Visual. Jurnal Rekam, 14(1).

Kholidi, I. (2016, Januari 13).Kesalehan Ritual dan Kesalehan Digital.NU Online.

https://www.nu.or.id/post/read/649 71/kesalehan-ritual-dan-kesalehandigital

Kosim, Muhammad, (2019). Peluang dan Tantangan Pendidikan Islam Era Industri 4.0: Strategi Mahasiswa PAI menjadi Pendidik Sejati., Jurnal Murabby: Jurnal Pendidikan Islam, Vol. 2 Nomor 2, September 2019

Kurniawan, B. (2018). Politisasi Agama di Tahun Politik: Politik PascaKebenaran di Indonesia dan Ancaman Bagi Demokrasi. Jurnal Sosiologi Agama, 12(1).

Lestari, A. S. (2017). Cyberculture: Membingkai Dakwah Kontemporer Masyarakat Modern. Zawiyah: Jurnal Pemikiran Islam, 3(1).

merdeka.com. (2016, Agustus 1).Kerusuhan di Tanjungbalai bukti media sosial jadi pisau bermata dua. merdeka.com. https://m.merdeka.com/peristiwa/ke rusuhan-di-tanjungbalai-buktimedia-sosial-jadi-pisau-bermatadua.html

Muthohirin, N. (2015). Radikalisme Islam dan Pergerakannya di Media Sosial.AFKARUNA: Jurnal IlmuIlmu Keislaman, 11(2).

Naim, N. (2016). Abdurrahman Wahid: Universalisme Islam dan Toleransi. Kalam: Jurnal Studi Agama dan Pemikiran Islam, 10(2).

Nasrullah, R., \& Rustandi, D. (2016). Meme dan Islam: Simulakra Bahasa Agama di Media Sosial. Ilmu Dakwah: Academic Journal for Homiletic Studies, 10(1).

Ningrum, D. J., Suryadi, \& Wardhana, E. C. (2018). Kajian Ujaran Kebencian di Media Sosial.Jurnal Ilmiah Korpus, II(III).

Nurjanah, E., Rusmana, A., \& Yanto, A. (2017).Hubungan Literasi Gigital 
dengan Kualitas Penggunaan EResources.Jurnal Lentera Pustaka, 3(2).

Oviyanti, F. (2013).Tantangan Pengembangan Pendidikan Keguruan di Era Global.Nadwa: Jurnal Pendidikan Islam, 7(2).

Qomar, M. (2019).Filsafat Pendidikan Islam Multidisipliner.Dalam Prosiding Seminar Nasional Program Studi PAI UMP 2019.UMP.

Rohayati. (2017). Budaya Komunikasi Masyarakat Maya (Cyber): Suatu Proses Interaksi Simbolik. Jurnal Sosial Budaya, 14(2).

Saepududin, D. M., Ahmad, N., \& Anwar, R. (2020).Makna Semantik Hamba dan Amal Saleh dalam Alquran.Jurnal Studi Al-Qur'an, 16(02).

Sanaky, H. A. H. (2003). Paradigma Pendidikan Islam.Safira Insani Press.

Sanjaya, W. (2015).Penelitian Pendidikan: Jenis, Metode dan Prosedur. Prenada Media Group.

Shihab, M. Q. (1997). Tafsir Al-Qur'an alKarim: Tafsir atas Surat-surat Pendek Berdasarkan Urutan Turunnya Wahyu. Pustaka Hidayah. Suharto, T. (2017). Indonesianisasi Islam: Penguatan Islam Moderat dalam Lembaga Pendidikan Islam di Indonesia. At-Tahrir: Jurnal Pemikiran Islam, 17(1).

Sujana, I. W. C. (2019).Fungsi dan Tujuan Pendidikan Indonesia.ADI WIDYA: Jurnal Pendidikan Dasar, 4(1).

Sukardi. (2015). Metodologi Penelitian Pendidikan: Kompetensi dan Praktiknya. Bumi Aksara.

Syahputra, M. C. (2020a). Jihad Santri Millennial Melawan Radikalisme di Era Digital: Studi Gerakan Arus Informasi Santri Nusantara di Media Sosial. Jurnal Islam Nusantara, 04(01).

Syahputra, M. C. (2020b). Pendidikan Multikultural dalam Budaya Nemui
Nyimah.EL-HIKMAH: Jurnal Kajian dan Penelitian Pendidikan Islam, 14(1).

Syahputra, M. C. (2020c). Gerakan Literasi Digital Pelajar Nahdlatul Ulama.TARBIYATUNA: Kajian Pendidikan Islam, 4(2).

Syamsirin.(2012). Tinjauan Filosofis Tantangan Pendidikan Islam Pada Era Globalisasi.Jurnal At-Ta'dib, $7(2)$.

'Uyun, Z. Q. (2020).Representasi Identitas Online-Offline dan Budaya Siber di Lingkungan Akademik.Serambi Academica: Jurnal Pendidikan, Sains, dan Humaniora, 8(1).

Wayong, Moh. (2017). Menuju Era Globalisasi Pendidikan: Tantangan dan Harapan bagi Perguruan Tinggi di Tanah Air. Jurnal Inspiratif Pendidikan, VI(2).

Zahid, R. A. (2013). Pendidikan Karakter: Sebuah Upaya Pembentuk Karakter Bangsa. Tribakti: Jurnal Pemikiran Keislaman, 24(2). 